\title{
Modeling of Flux Linkage Characteristics of Switched Reluctance Motor
}

\author{
Anwar Ahmed Memon*, Ali Asghar Memon, Muhammad Aslam Uqaili and Mukhtiar Ali Unar \\ Mehran University of Engineering and Technology, Jamshoro, Pakistan; anwar.memon@faculty.muet.edu.pk
}

\begin{abstract}
The increasing popularity of the switched reluctance machine has created more challenges to present it as a good performer machine under different operational conditions. For modeling and simulation of the machine, the necessity of static characteristics, in particular, flux linkage characteristics which look like the base stone for initialization of simulation is unavoidable. The importance of flux linkage characteristics, and how other data tables such as inverter flux linkage characteristics, co energy and static torque table are obtained are presented in this work. This paper describes a set of equations for modeling of the flux linkage characteristics of switched reluctance machine and also hardware for the 3-phase machine is presented.
\end{abstract}

Keywords: Flux Linkage Characteristics, Inductance Profile, Switched Reluctance Machine

\section{Introduction}

Switched Reluctance (SR) motor is the advanced version of the stepper motor with a simple construction as rotor excludes the winding. Stepper motor is an open loop motor whereas the SR motor is a closed loop motor. SR Motor could be used for a variety of applications, starting from household to industry. This machine could not be connected directly with dc supply but it needs a suitable electronic converter. This machine is available in different phase count e.g. single phase to multiple phases.

The rotation in the machine is due to the magnetic attraction of stator poles on its nearest rotor poles. The electrical energy is supplied to the machine when electronic switches preferably IGBTs (Insulated Gate Bipolar Transistor), MOSFET (Metal OxideSemi-Conductor Field Effect Transistor) are closed, the unutilized energy is then transferred back to same energy source as the switches are opened. Figure 1 shows a three-phase machine with 6/4 phase poles. The machine in motoring mode is switched on when the slope of inductance is positive and the value of inductance is decreased. Alternatively, if the machine is switched on at decreased slope of inductance, it will count a generating mode. The inductance profile is shown in Figure 2. A variety of converters are added for the operation of this machine ${ }^{1-5}$.

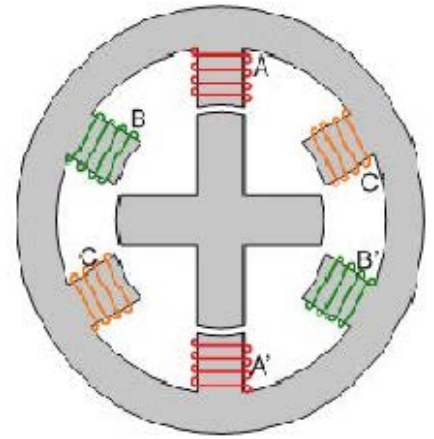

Figure 1. 6/4 pole switch reluctance motor.

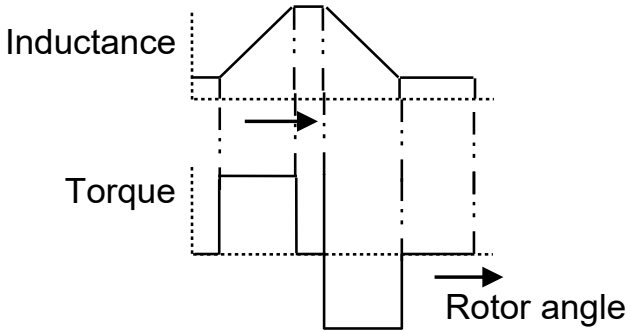

Figure 2. Inductance profile of SR motor.

\section{Static Characteristics}

The procedure of measurement and modeling of static characteristics are discussed $i^{6}$. The characteristics have 
been measured in Lab VIEW. These characteristics have been compared with simulation results. Accurate prediction of the motor parameters and static characteristics of SRM play an important role in the simulation of SRM drive ${ }^{7}$. In this paper, the performance of the 4-phase motor is experimentally analyzed under a fixed current and angle control. A different technique for measurement of static characteristics is used in ${ }^{8}$. The $\Psi$-i for the different angle used in this method. The author claims the avoidance of electrical/electronic problems of measurement. Another work is reported $\mathrm{in}^{9}$. An experimental study is performed in $^{10}$ to obtain the magnetization and static torque characteristics of commercially available Switched Reluctance motor. The obtained results are compared with the calculated results of static torque. Static torque is calculated from the data of Flux linkage. The D.C excitation method is used $\mathrm{in}^{11}$. This method evaluates the rising and falling current. For determination of static flux linkage characteristics of Switched Reluctance Motor, the rising current method generates the initial transients that have a computation discrepancy. The electromagnetic characterization of $8 / 6 \mathrm{SRM}$ is described. Finite element method is used to obtain the magnetic characteristics.

A series of experimental tests are performed in $^{12}$. The experimental test concludes that FEM has some limitations when the phase current has very low values.

A Digital Signal Processor (DSP) based SRM drive system is used for the investigation of static characteristics. Matlab/Simulink models are generated ${ }^{8}$. Inductance and torque characteristics are also obtained by experimental methods.

An online winding resistance estimation technique is used to find flux linkage values for linear SRM. Theoretical derivation and the actual implementation of the proposed method is addressed in ${ }^{13}$. By comparison of the search coil method scheme and the static resistance schemes with the experimental results, the validity is addressed.

Flux linkage and static torque characteristics of Switched reluctance motor are calculated by the digital signal processing method ${ }^{14}$. Errors in measurement are discussed in different aspects. The moving average filter is used to reduce noise and errors. The accuracy of the proposed method is verified by different methods like co-energy, FEM and LCR meter. The static flux-linkages versus current characteristics with different angles from unaligned to fully aligned position. These characteristics are used as a lookup table. The same data is then obtained for computation of co-energy which is required for the next needed data of static torque.

\section{A Mathematical Modeling of Switched Reluctance Motor based on Static Characteristics}

There is no denying fact that the significant performance of the machine requires the of static characteristics. Mathematical equations of instantaneous torque and coenergy of the magnetic field are defined respectively as,

$$
T=\left(\frac{\partial w^{\prime}}{\partial \theta}\right)_{i=\text { constant }}, w^{\prime}=\int_{0}^{i} \psi d i
$$

where, $T$ represents torque, $w^{\prime}$ is a co-energy, $\theta$ indicates an rotor angle, $i$ is instantaneous current, $\psi$ denotes flux linkage and $\frac{\partial}{\partial \theta}$ is the differential operator.

In eq. 2 , given below

$$
T=-\left(\frac{\partial w_{f}}{\partial \theta}\right)_{\psi=\text { constant }}, w_{f}=-\int_{0}^{\psi} i d \psi,
$$

where $w_{f}$ is the stored energy. It is noted that the data of static characteristics are very suitable to describe the prediction of instantaneous, the magnetic nature and steady-state performance of switched reluctance motor. Meanwhile, the governing differential voltage equations for the handling of the data can be written as in the form of an ordinary differential operator as

$$
T=\frac{i^{2}}{2} \frac{d L}{d \theta}, \psi=i L, w_{f}=w=\frac{i^{2} L}{2},
$$

Equation $\left(3_{1,2,3}\right)$ represents the ordinary governing differential equations of torque, flux linkage, and co-energy respectively. Here, a small "dwell" at maximum inductance will happen if the rotor and stator pole arcs are different, but conversely, if the inter-polar arc of rotor exceeds the stator pole arc, of course, a small "dwell" at minimum inductance will occur.

The governing ordinary differential equations of a Switched reluctance motor with phase voltage can be described as

$$
\begin{aligned}
& V=\frac{d \lambda}{d t}+R i, V=\frac{d L(\theta)}{d \theta} i \omega+\frac{d \lambda}{d t} L(\theta), \\
& V i=\omega i^{2} \frac{d L}{d \theta}+L i \frac{d i}{d t} .
\end{aligned}
$$


The equation (4) is obtained by multiplying the voltage with current, such equation is usually called the governing differential equation of the rate of flow of energy. While for equations (4), $V$ shows the DC bus voltage, $\lambda$ is flux linking the phase coil, $R$ denotes is the phase winding resistance and $i$ represents the instantaneous phase current. For equations (4), $L(\theta)$ is the instantaneous phase inductance, $\omega$ presents the rotor speed and $\theta$ denoted the rotor angular position.

\section{An Experimental Setup}

The experimental rig of a three-phase switched reluctance machine is shown in Figure 3.

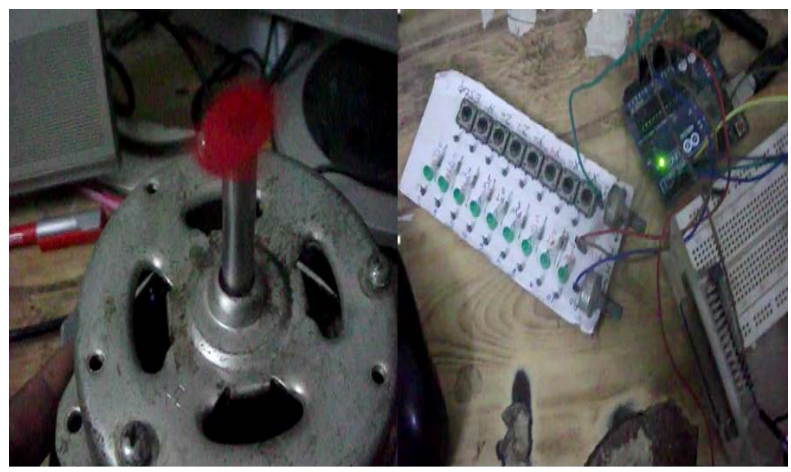

Figure 3. An existing SR machine.

The obtained results are shown in Figures 4 and 5 with a difference that on $\mathrm{x}$-axis, one labeled as current whereas, in Figure 5 it is against rotor position.

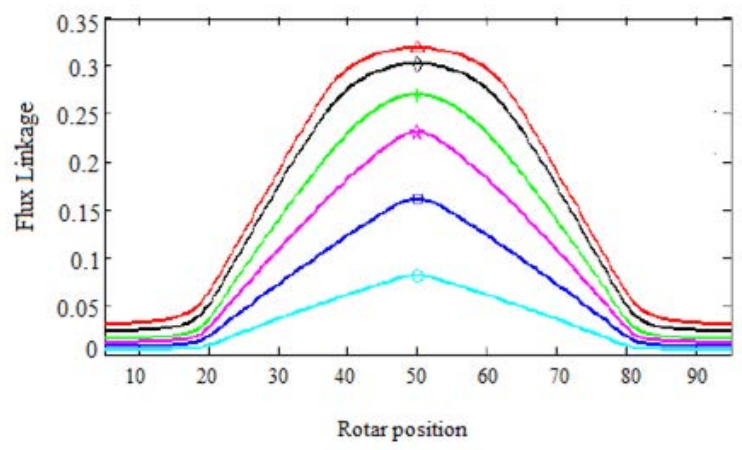

Figure 4. Magnetization characteristics at different current values.

\section{Conclusion}

The set of flux linkage characteristics are produced at a different range of stator current and rotor position. The

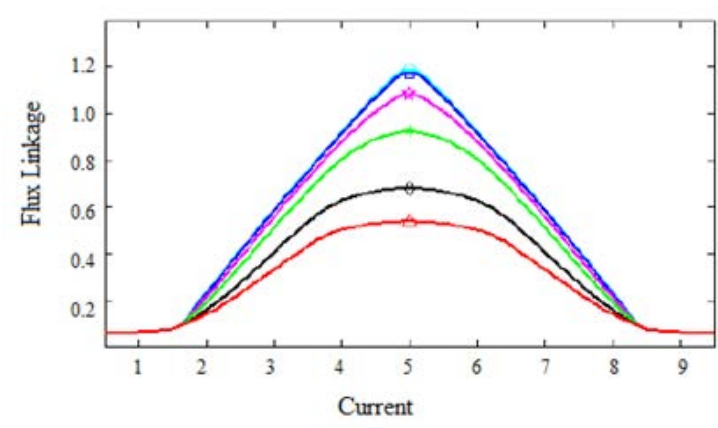

Figure 5. Magnetization characteristics at different rotor positions.

hardware is successfully developed and flux linkage characteristics are extracted from the data of induced EMF. The trend of obtained results shows good agreement with those seen in literature for different pole machines.

\section{References}

1. Sayeed M, Husain I, Elbuluk ME. Energy-efficient C-dump converters for switched reluctance motors. IEEE Transactions on Power Electronics. 1997; 12(5):912-21. https://doi.org/10.1109/63.623010

2. Jorge FM, Estima JO, Gameiro NS, Cardoso AJM. A new diagnostic technique for real-time diagnosis of power converter faults in switched reluctance motor drives. IEEE Transactions on Industry Applications. 2014; 50(3):185460. https://doi.org/10.1109/TIA.2013.2279898

3. Ronanki D, Williamson SS. Modular multilevel converters for transportation electrification: Challenges and opportunities. IEEE Transactions on Transportation Electrification. 2018; 4(2):399-407.https://doi.org/10.1109/ TTE.2018.2792330

4. Gonzalez SA, Verne SA, Valla MI. Multilevel converters for industrial applications. CRC Press; 2016. https://doi. org/10.1201/b15252

5. Mahmoud, SM, El-Sherif MZ, Abdel-Aliem ES, Nashed MNF. Studying different types of power converters fed switched reluctance motor. International Journal of Electronics and Electrical Engineering. 2013; 1(4):281-90. https://doi.org/10.12720/ijeee.1.4.281-290

6. Stephenson JM, Corda J. Computation of torque and current in doubly salient reluctance motors from nonlinear magnetization data. Proceedings of the Institution of Electrical Engineers. 1979 May; 126(5):393-6. https://doi. org/10.1049/piee.1979.0095

7. Moallem M, Ong C-M. Predicting the steady-state performance of a switched reluctance machine. IEEE Transactions 
on Industry Applications. 1991 Nov/Dec; 27(6):1087-97. https://doi.org/10.1109/28.108459

8. Sharma VK, Murthy SS, Singh B. An improved method for the determination of saturation characteristics of switched reluctance motors. IEEE Transactions on Instrumentation and Measurement. 1999 Oct; 48(5):995-1000,1097. https:// doi.org/10.1109/19.799660

9. Chancharoensook P, Rahman MF. Magnetization and static torque characterization of four- phase switched reluctance motor. IEEE Transactions on Experimental Investigations; 2001. p 456-60.

10. Gobbi R, Sahoo NC, Rajandran RV. Rising and falling current methods for measurement of flux- linkage characteristics of switched reluctance motors: A comparative study. First International Power and Energy Conference PEC, 2006 Nov 28-29, IEEE Putrajays, Malaysia; 2006. https://doi.org/10.1109/PECON.2006.346681

11. Asgharmemon A, Hussain I, Daupoto J. Modeling of static characteristics of switched reluctance motor. Mehran University Research Journal of Engineering and Technology. 2013 Jan; 32(1).

12. Memon AA. Prediction of compound losses in a switched reluctance machine and inverter. Ph.D. Thesis, University of Leeds (School of Electronic and Electrical Engineering), Leeds, UK; 2012 Mar.
13. Semsudin M, Corda J, Samaka S. Computation of static, steady-state and dynamic characteristics of the switched reluctance motor. ATKAAF. 2002; 43(3-4):109-17.

14. Corda J, Stephenson JM. Analytical estimation of minimum and maximum inductances of a double-salient motor. Proceeding International Conference on Stepping Motors and Systems, Leeds, UK; 1979 Sep. p. 50-9.

15. Corda J. Switched reluctance machine as a variable -speed drive. Ph.D. thesis, University of Leeds (School of Electronic and Electrical Engineering), Leeds, UK; 1979.

16. Memon AA, Shah SAA, Shah W, Baloch MH, Kalo GS. A flexible mathematical model for dissimilar operating modes of a Switched Reluctance Machine. IEEE Access Digital Object Identifier; 2018 Feb 7.

17. Gan $\mathrm{C}$, et al. A review on machine topologies and control techniques for low-noise switched reluctance motors in electric vehicle applications. 2018 May 16; 6.

18. Corda J, Jamil SM. Experimental determination of equivalent-circuit parameters of a tubular switched reluctance machine with solid-steel magnetic core. IEEE Transactions on Industrial Electronics. 2010 May; 57(1):304-10. https:// doi.org/10.1109/TIE.2009.2026762

19. Memon AA, Shaikh MM. Input data for mathematical modeling and numerical simulation of switched reluctance machines. 2017 Oct; 14:138-42. https://doi.org/10.1016/j. dib.2017.07.044 PMid:28861447. PMCid:PMC5567386 